\section{Childbirth with fetal pelvis presentatio - challenge in modern obstetrics}

Borlja Mijailovic Radenka1, Skender Maja ${ }^{2}$, Avramovic Ljiljana ${ }^{1}$, Mirjana Pavlovic Raicevic ${ }^{2}$, Aleksandar Dukic ${ }^{1}$, Vesna Ljubic ${ }^{2}$

${ }^{1}$ Hospital for Gynecology and Obstetrics, Clinical Hospital Center Zemun- Belgrade

${ }^{2}$ Neonatal services, Hospitals for Gynecology and Obstetrics, Clinical Hospital Center Zemun- Belgrade

\section{Abstract}

The aim was to determine the incidence of fetal breech presentation at term, the factors that determine how the impact of labor and mode of delivery on neonatal outcome in pregnancies with a fetus in breech presentation pelvic presentation is a form of the longitudinal position of the fetus, which leads the pelvis and occurs in approximately $3 \%$ of pregnancies. Numerous studies have shown contradictory results regarding the optimal mode of delivery in breech presentation of fetus. A retrospective study at the Hospital of Gynecology and Obstetrics, University Hospital Zemun-Belgrade in the period 01.01.2009-31.12.2011 year. We analyzed data obtained from the delivery protocol, computer databases and annual reports.study involved 111 pregnant women in the forward singleton pregnancy (37-41 weeks gestation) with fetal pelvis. We analyzed and compared the group of patients who delivered their babies vaginally and the group of patients who delivered their babies by caesarean section (emergency and planned). Analyzed and compared the following parameters: maternal age, parity, gestational age tudnoće, premature rupture of membranes, weight and head circumference fetus at birth, Apgar score and neonatal complications. The data were analyzed by descriptive and analytical statistics. Results are presented tables and graphs. The study period was performed 4665 deliveries, with 111 deliveries in futures fetuses in breech presentation, which is $2.4 \%$. Women delivered vaginally was $79(71 \%)$, emergency caesarean section $17(15 \%)$, a planned caesarean section $15(14 \%)$ pregnant women. The study showed a statistically significant difference in parity $(\mathrm{C} 2=6.23 \mathrm{p}<0,05)$, with greater participation in the group of primiparas cesarean section, gestational age $(t=5.23 \mathrm{p}<0,01)$, weight and head circumference $(\mathrm{t}=4.37, \mathrm{t}=2.47 \mathrm{p}<0,01)$,

\section{Porođaj kod prednjačeće karlice ploda- izazov u savremenom akušerstvu}

Borlja Mijailović Radenka ${ }^{1}$, Skender Maja ${ }^{2}$, Avramović Ljiljana ${ }^{1}$, Pavlović Raičević Mirjana ${ }^{2}$, Dukić Aleksandar ${ }^{1}$, Ljubić Vesna ${ }^{2}$

${ }^{1}$ Bolnica za ginekologiju i akušerstvo KBC Zemun-Beograd, Beograd, Srbija

${ }^{2}$ Neonatološka služba Bolnice za ginekologiju i akušerstvo KBC Zemun-Beograd, Beograd, Srbija

\section{Apstrakt}

Cilj studije je bio utvrđivanje učestalosti karlične prezentacije ploda u terminu, faktora koji determinišu način porođaja i uticaj načina porođaja na neonatalni ishod u trudnoćama sa plodom $\mathrm{u}$ karličnoj prezentaciji. Karlična prezentacija je vid uzdužnog položaja ploda, gde prednjači karlica i javlja se u oko 3\% terminskih trudnoća. Brojna istraživanja dala su kontradiktorne rezultate $u$ vezi sa optimalnim načinom završavanja porođaja kod karlične prezentacije ploda. Sprovedena je retrospektivno istraživanje u Bolnici za ginekologiju i akušerstvo KBC Zemun-Beograd u periodu od 01.01.2009-31.12.2011. godine. Analizirani su podaci dobijeni iz protokola porođaja, kompjuterske baze podataka i godišnjih izveštaja. Istraživanjem je obuhvaćeno 111 trudnica u terminskoj jednoplodnoj trudnoći (37-41 nedelje gestacije) sa prednjačećom karlicom ploda. Analizirna je i upoređivana grupa pacijentkinja koje su porođene vaginalno i grupa pacijentkinja koje su porođene carskim rezom (hitnim i planiranim). Analizirani su i upoređivani sledeći parametri: starost majke, paritet, gestacijska starost tudnoće, prevremena ruptura plodovih ovojaka, telesna masa i obim glavice ploda na rođenju, Apgar scor i neonatalne komplikacije. Dobijeni podaci, analizirani su metodama deskriptivne i analitičke statistike. Rezultati su prikazani tabelarno i grafički. $\mathrm{U}$ ispitivanom periodu obavljeno je 4665 porođaja, sa 111 porođaja kod terminskih plodova u karličnoj prezentaciji, što čini $2,4 \%$. Vaginalnim putem je porođeno $79(71 \%)$, hitnim carskim rezom $17(15 \%)$, a planiranim carskim rezom $15(14 \%)$ trudnica. Istraživanje je pokazalo statistički značajnu razliku u paritetu $(C 2=6,23 p<0,05)$, sa većim učešćem prvorotki u grupi carskog reza, gestacijskoj starosti $(\mathrm{t}=5,23 \mathrm{p}<0,01)$, telesnoj masi i obimu glavice 
premature rupture of membranes, $(\mathrm{C} 2=7.72 \mathrm{p}<0,01)$ and gender structure $(\mathrm{C} 2=4.03 \mathrm{p}<0,05)$. The most common indication for elective Caesarean section was prolonged pregnancy, and for an emergency cesarean section because of the delivery routes. There was no statistically significant difference in age of the mother $\mathrm{t}=1.08, \mathrm{p}>0,05$, the values of Apgar score in 5 minutes $t=1.67 p>0,05$, neurological changes $p=0.292$ and birth trauma, $p=0.292$ between two groups of neonates. The values of ul minute Apgar score were at the limits of statistical significance $p=1.97$ $\mathrm{p} \geq 0.05$. Vaginal delivery in breech presentation, fetal, obstetric an acceptable range, while respecting the principles of good obstetric practice, there is no increase in neonatal morbidity.

Key words: pelvic presentation, delivery, neonatal outcome ploda $(\mathrm{t}=4,37, \mathrm{t}=2,47 \mathrm{p}<0,01)$, prevremenoj rupturi plodovih ovojaka, $(\mathrm{C} 2=7,72 \mathrm{p}<0,01)$ i polnoj strukturi $(\mathrm{C} 2=4,03 \mathrm{p}<0,05)$. Najčešća indikacija za planirani carski rez je bila prolongirana trudnoća, a za hitan carski rez, nenapredovanje porođaja. Nije pronađena statistički značajna razlika u materalnim godinama $\mathrm{t}=1,08 \mathrm{p}>0,05$, vrednostima Apgar scora u 5 minutu $\mathrm{t}=1,67 \mathrm{p}>0,05$, neurološkim promenama $\mathrm{p}=0,292 \mathrm{i}$ porođajnim traumama $\mathrm{p}=0,292$ neonatusa između ispitivanih grupa. Vrednosti Apgar scora u 1 minutu su bile na granicama statističke značajnosti $t=1,97$ $p \geq 0,05$. Vaginalni porođaj pri karličnoj prezentaciji ploda, predstavlja prihvatljiv akušerski izbor,uz poštovanje principa dobre akušerske prakse,ne dolazi do povećanja neonatalnog morbiditeta.

Ključne reči: karlična prezentacija, porođaj, neonatalni ishod

\section{Uvod}

Karlična prezentacija je vid uzdužnog položaja ploda, gde prednjači karlica i javlja se u oko 3\% terminskih trudnoća ${ }^{1}$. Faktori koji su povezani sa karličnom prezentacijom mogu poticati od majke (anomalija materice, miomatozna materica, multiparitet sa oslabljenim tonusom materice...), ploda (intrauterini zastoj u rast, fetalne anomalije, fetalna smrt, kratak pupčanik...) i patoloških faktora vezanih za tok trudnoće (povećana ili smanjena količina plodove vode, prednjačeća posteljica, prevremeni porođaj). ${ }^{2}$ Porođaj kod ploda sa prednjačećom karlicom praćen je većim perinatalnim morbiditetom i mortalitetom u odnosu sa porođaj sa prednjačećom glavicom ploda. ${ }^{3}$ Shodno tome, optimalni način porođaja kod ploda sa karličnom prezentacijom ostaje kontroverza. ${ }^{4}$ Vaginalni porođaj podrazumeva visok rizik od ozbiljnih komplikacija: prolapsa pupčanika, aspiracije amnionske tečnosti, materalnih i fetalnih komplikacija u toku porođaja i povećanja učestalosti operativnog završavanja porođaja. ${ }^{3,5} \mathrm{Da}$ bi se smanjio mortalitet i morbiditet dece pri vaginalnom porođaju, preporučena je liberalizacija carskog reza. ${ }^{6}$

Međutim, brojna istraživanja dala su kontradiktorne rezultate u vezi sa optimalnim načinom završavanja porođaja kod karlične prezentacije ploda. ${ }^{4,7}$ Pojedini autori zagovaraju operativno završavanje porođaja, te stopa planiranog carskog reza, kao načina završavanja trudnoća kod ploda sa prednjačećom karlicom dostiže i 100\%, ali su stavovi o opravdanosti visokog učešća CR kontroverzni. $8 \mathrm{~S}$ druge strane, mnoge druge studije su pokazale da, uz poštovanje uslova za vaginalno završavanje porođaja (plod telesne mase od 2000-3800g, ginekoidna karlica, nepostojeća disproporcija, isključena hiperekstendirana fetalna glavica i fetalne anomalije, koje bi dovele do mehaničhih problema tokom porođaja, kao što je hidrocefalus), vaginalni porođaj, predstavlja prihvatljiv akušerskih izbor za terminaciju trudnoća sa karličnom prezentacijom ploda. ${ }^{9}$ Američko udruženje akušera i ginekologa (ACOG) je 2006. godine, zamenio svoje ranije restriktivne smernice sa novim verzijama u korist odabranih vaginalnih porođaja kod karlične prezentacije ploda, zaključivši da je „u ustanovama gde su planirani vaginalni porođaji uobičajena praksa i kada su ispunjeni strogi kriterijumi pre i tokom porođaja, vaginalni planirana porođaj jednoplodnih fetusa u karličnoj prezentaciji u terminu, ostaje sigurna opcija koja se može ponuditi ženama". ${ }^{10}$

Cilj rada je bio utvrđivanje učestalosti karlične prezentacije ploda u terminu, faktora koji determinišu način porođaja i uticaj načina porođaja na neonatalni ishod u trudnoćama sa plodom u karličnoj prezentaciji. 


\section{Materijal i metode}

Sprovedeno je retrospekivno istraživanje u Bolnici za ginekologiju i akušerstvo KBC Zemun-Beograd u periodu od 01.01.2009-31.12.2011 godine. Analizirani su podaci dobijeni iz protokola porođaja, kompjuterske baze podataka i godišnjih izveštaja. Istraživanjem je obuhvaćeno 111 trudnica u terminskoj jednoplodnoj trudnoći (37-41 nedelje gestacije) sa prednjačećom karlicom ploda. Analizirna je i upoređivana grupa pacijentkinja koje su porođene vaginalno (VP) i grupa pacijentkinja koje su porođene carskim rezom (CR) (hitnim i planiranim). Analizirani su i upoređivani sledeći parametri: starost majke, paritet, gestacijska starost tudnoće, prevremena ruptura plodovih ovojaka, telesna masa i obim glavice ploda na rođenju, Apgar scor i neonatalne komplikacije. Paritet je definisana prema broju prethodnih porođaja, gestacijske starosti preko 28 završenih nedelja gestacije (uključujući i mrtvorođenu decu). Procena gestacijske starosti je bila zasnovana na datumu poslednje menstruacije i/ili rutinskim ultrazvučnim pregledima pre završetka 20 gestacijske nedelje. Način porođaja je definisan kao planirani ili hitni carski rez i vaginalni porođaj. Planirani carski rez je definisana kao način porođaja pre početka aktivne faze porođaja, a hitan carski rez, nakon početka aktivne faze porođaja. Istraživanjem nisu obuhvaćene trudnice kod kojih je indikacija za carski rez bila, prethodno operativno završavanje porođaja Vaginalni porođaj je sproveden od strane iskusnih akušera uz prisustvo neonatologa na porođaju. Dobijeni podaci, analizirani su metodama deskriptivne i analitičke statistike. Rezultati su prikazani tabelarno i grafički.

\section{Rezultati}

U periodu od 01.01.2009-31.12.2011 godine u Bolnici za ginekologiju i akušerstvo KBC Zemun-Beograd obavljno je 4665 porođaja, sa 111 porođaja kod terminskih plodova u karličnoj prezentaciji, što čini 2,4\%.

Vaginalnim putem je porođeno $79(71 \%)$, hitnim carskim rezom 17(15\%), a planiranim carskim rezom 15(14\%) trudnica (Grafikon 1.).

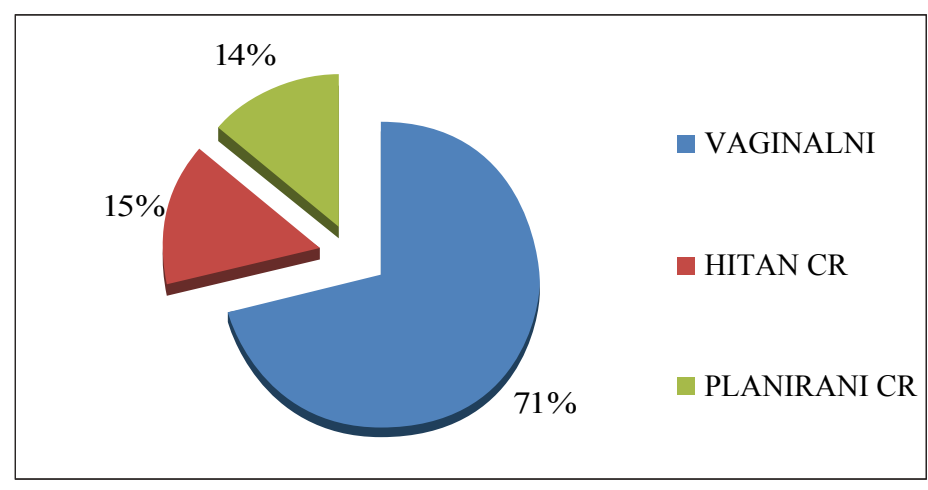

Grafikon 1. Način završetka porođaja kod karlične prezentacije ploda

Uočena je statistički značajna razlika u načinu završavanja porođaja u odnosu na paritet 87,5\% u grupi žena sa carskim rezom čine prvorotke. $\mathrm{C} 2=6,23, \mathrm{p}<0,05$ (Tabela 1.).

\begin{tabular}{|c|c|c|c|}
\hline Paritet & Vaginalni porođaj & Carski rez & Ukupno \\
\hline Prvorotke & 52 & 28 & 80 \\
\hline Drugorotke & 18 & 4 & 22 \\
\hline Višerotke & 9 & - & 9 \\
\hline Ukupno & 79 & 32 & 111 \\
\hline
\end{tabular}

Tabela 1. Način završavanja porođaja u odnosu na paritet 


\section{ORIGINALNI RADOVI}

Nije uočena statistički značajna razlika u načinu završavanja porođaja u odnosu na materalne godine $t=1,08$, $\mathrm{p}>0,05$ (Grafikon 2.).

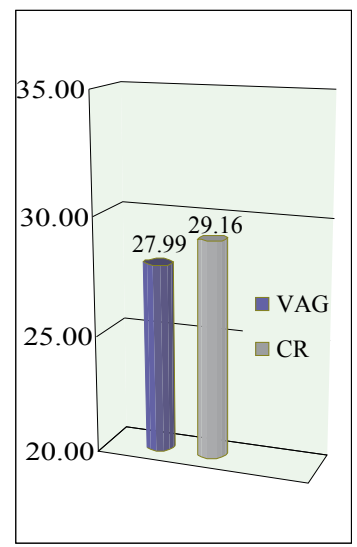

Grafikon 2. Struktura materalnih godina u odnosu na način završavanja porođaja

Zabeležena je veća gestacijska starost trudnoće u grupi žena, koje su porođene carskim rezom $\mathrm{t}=5,23$ $\mathrm{p}<0,01$ ( Grafikon 3.).

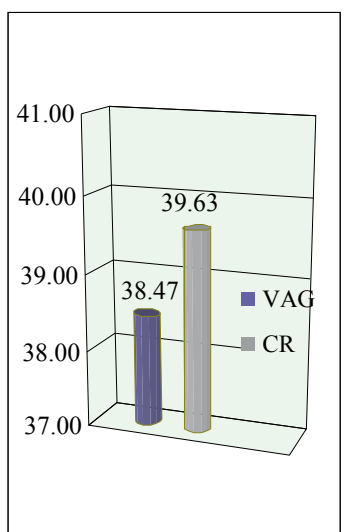

Grafikon 3. Gestacijska starost trudnoće u odnosu na način završavanja porođaja

U grupi koja je porođena carskim rezom zabeležena je veća telesna masa ploda i obima glavice novorođenčeta uz statistički značajnu razliku između ispitivanih grupa $\mathrm{t}=4,31, \mathrm{p}<0,01 \mathrm{i} t=2,47 \mathrm{p}<0,05$ ( Grafikon 4 i 5.).

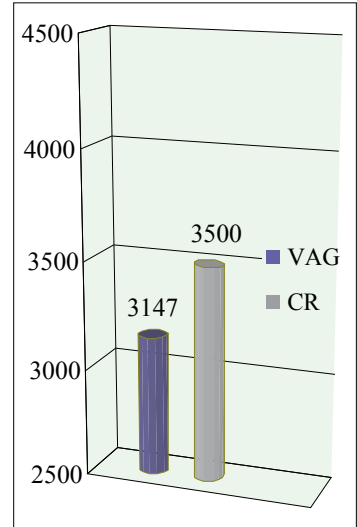

Grafikon 4. Telesna masa ploda u odnosu na način završavanja porođaja 


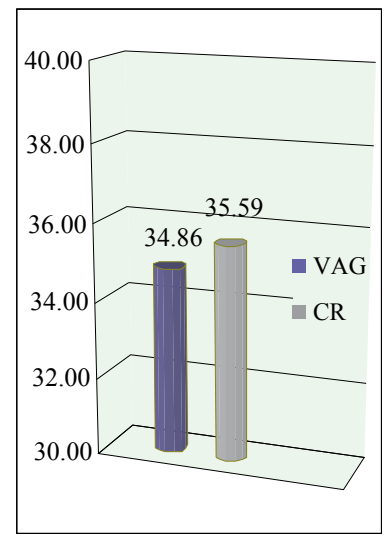

Grafikon 5. Obim glave ploda u odnosu na način završavanja porođaja

Kod trudnica koje su porođene hitnim carskim rezom, postoji znatno veći procenat prevremene rupture plodovih ovojaka (PROM) ( $(23 \%$ VP vs. $64 \% \mathrm{CR})$ uz statistički značajnu razliku u odnosu na grupu porođenu vaginalnim putem. $\mathrm{C} 2=7,72 \mathrm{p}<0,01$ (Grafikon 6.).

Utvrđena je statistički značajna razlika u polnoj strukturi novorođenčadi pri vaginalnom $(66 \%$ Ž vs. $38 \% \mathrm{M})$

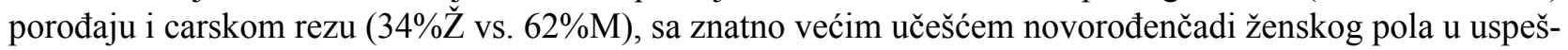
nom vaginalnom porođaju. $\mathrm{C} 2=4,03 \mathrm{p}<0,05$ (Grafikon 7.).

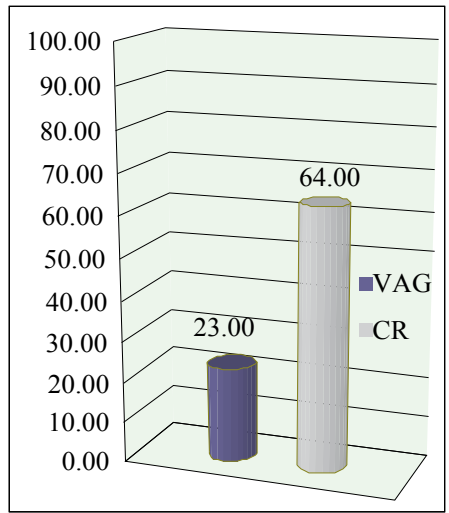

Grafikon 6. Udeo PROM-a u odnosu na način završavanja porođaja

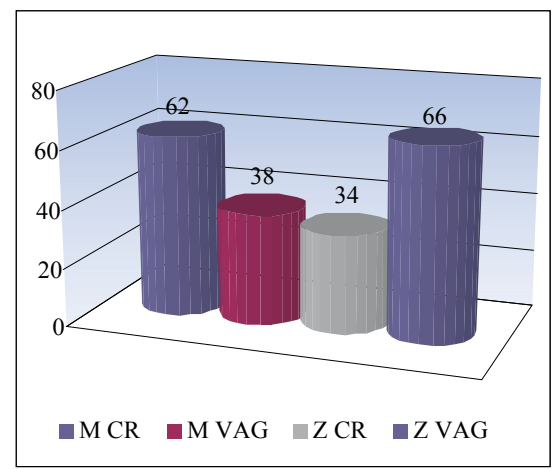

Grafikon 7. Polna struktura u odnosu na na način završavanja porođaja 


\section{ORIGINALNI RADOVI}

U toku našeg istraživanja, zabeležili smo da prolongirana trudnoća (60\%), dominira kao indikacija pri planiranom carskom rezu, a nenapredovanje porođaja $(58,8 \%)$, kao indikacija pri hitnom carskom rezu (Tabele 2 i 3.).

\begin{tabular}{|c|c|}
\hline indikacije za planirani carski rez & broj porođaja \\
\hline prolongirana trudnoća & 9 \\
\hline makrozomija ploda & 4 \\
\hline Disproporcija & 2 \\
\hline Ukupno & 15 \\
\hline
\end{tabular}

Tabela 2. Indikacije za planiran carski rez

\begin{tabular}{|c|c|}
\hline indikacije za hitan carski rez & broj porođaja \\
\hline nenapredovanje porođaja & 10 \\
\hline asfiksija fetusa & 3 \\
\hline disproporcija & 4 \\
\hline ukupno & 17 \\
\hline
\end{tabular}

Tabela 3. Indikacije za hitan carski rez

Prosečne vrednosti Apgar scora u prvom minutu (8,44VP vs. 8,81CR) su na granici statističke značajnosti $\mathrm{t}=1,97 \mathrm{p} \geq 0,05$ a u petom minutu $(9,51 \mathrm{VP}$ vs. 9,78CR), nisu pokazale statistički značajnu razliku između ispitivanih grupa. $\mathrm{t}=1,67 \mathrm{p}>0,05$ (Grafikoni 8 i 9.).

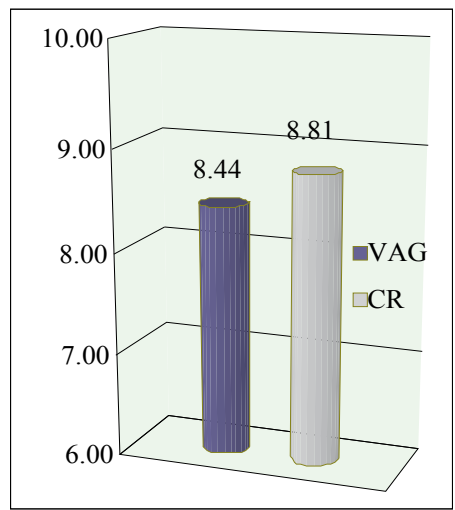

Grafikon 8. Apgar score $1 \mathrm{u}$ odnosu na način završavanja porođaja

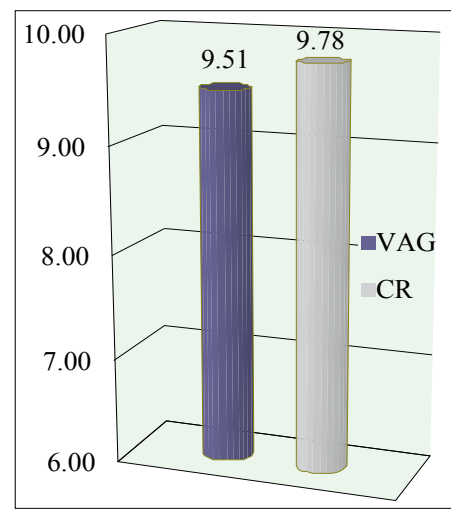

Grafikon 9. Apgar score 5 u odnosu na način završavanja porođaja

Nije uočena statistički značajna razlika u prisustvu neurološke patologije $p=0,292$ i porođajnih trauma $\mathrm{p}=0,292$ između dve grupe ispitivanih novorođenčadi (Tabele 4 i 5.).

\begin{tabular}{|c|c|c|}
\hline Neurološka patologija & $\begin{array}{c}\text { Vaginalni } \\
\text { porođaj } \\
\text { porođaja }\end{array}$ & Carski rez \\
\hline $\begin{array}{c}\text { hipoksičnoishemična } \\
\text { encefalopatija }\end{array}$ & 1 & 1 \\
\hline hipertonus & 1 & 1 \\
\hline $\begin{array}{c}\text { intraventrikularna } \\
\text { hemoragija II }\end{array}$ & 3 & \\
\hline dilatacija komora & 1 & 2 \\
\hline Ukupno & 6 & \\
\hline
\end{tabular}

Tabela 4. Neurološka patologija ploda u odnosu na način završavanja porođaja

\begin{tabular}{|c|c|c|}
\hline Porođajne traume & $\begin{array}{c}\text { Vaginalni } \\
\text { porođaj } \\
\text { porođaja }\end{array}$ & Carski rez \\
\hline Kefalhematom & 2 & - \\
\hline fraktura klavikule & 1 & - \\
\hline pareza facijalisa & - & 2 \\
\hline pareza pl.brahijalisa & 4 & - \\
\hline povrede mekih tkiva & 2 & - \\
\hline miogeni tortikolitis & 1 & - \\
\hline ukupno & $10(6$ beba $)$ & 2 \\
\hline
\end{tabular}

Tabela 5. Porođajne traume ploda u odnosu na način završavanja porođaja 
Istraživanje je pokazalo uspešno završavanje porođaja vaginalnim putem pri karličnoj prezentaciji ploda u $71 \%$ slučajeva, a bez povećanja neonatalnog morbiditeta u odnosu na grupu rođenih carskim rezom.

\section{Diskusija}

Učestalost karlične prezentacije u posmatranom periodu u našem istraživanju bila je $2,4 \%$, što se poklapa sa prijavljenim podacima drugih studija. ${ }^{1}$ Porođaj kod karlične prezentacije terminskog ploda i kroz istoriju, a i danas ostao je kontroverza. Osim perinatoloških komplikacija, koje prate vaginalni porođaj pri karličnoj prezentaciji ploda i nemedicinski, dodatni faktori, kao što su prava pacijenta, prisustvo i angažovanje medija, advokata za najmanji propust i grešku, uz manje iskusnih i neobučenih akušera za vaginalni porođaj pri karličnoj prezentaciji ploda, doprinosi da se akušeri, a radi oslobađanja od stresa i odgovornosti sve češće odlučuju za carski rez. ${ }^{7,8}$ Shodno tome, neki autori preporučuju izborni carski rez za sve slučajeve karlične prezentacije ploda u terminu, te postoje bolnice sa $100 \%$ izbornog carskog reza. ${ }^{8} \mathrm{U}$ našem istraživanju procenat carskog reza je $32 \%$, a imajući u vidu da veliki broj studija ukazuje da je vaginalni porođaj prihvatljiv akušerski izbor, te učešće izbora vaginalnog porođaja koji se kreće od 31\% Nemačkoj do 70\% u Francuskoj, vaginalni porođaj sa $71 \%$, predstavlja akušerski izbor u našoj ustanovi, sa primetnim porastom uspešno završenih vaginalnih porođaja kod drugorotki i višerotki i do $87 \% .{ }^{11}$ Iako su mnoge studije utvrdile pozitivnu korelaciju između starosti majke i povećane incidence carskog reza, mi nismo našli tu povezanost u našem istraživanju, što se može objasniti ranim stupanjem u brak, žena koje gravitiraju ka našem porodilištu. ${ }^{12}$

Mnogi autori su izvestili da je veća uspešnost za vaginalni porođaj pri karličnoj prezentaciji u slučaju spontanog započinjanja aktivne faze porođaja, uz mogućnost korišćenja stimulacije za pojačavanje već postojećih kontrakcija, ali je indukcija porođaja kod karlične prezentacije ploda, kontraindikovana. ${ }^{13}$ Utvrdili smo u našoj studiji veću gestacijsku starost trudnoće u grupi porođenih carskim rezom, a kao indikacija za planirani carski rez u $60 \%$ slučajeva zabeležili smo prolongiranu trudnoću.

Konstatovano je da se perinatalni morbiditet i mortalitet pri vaginalnom porođaju povećava sa porastom telesne mase ploda, predloženi limiti porođajne težine kreću se od 3500g do 4500g. Prema ACOG-u, optimalna telesna masa ploda u karličnoj prezentaciji gde se može dozvoliti probni vaginalni porođaj kreće do $3800 \mathrm{~g} .{ }^{10,14}$

U našoj studiji, prosečna težina kod vaginalne grupe iznosi $3150 \mathrm{~g}$, a u grupi carskog reza $3500 \mathrm{~g}$. Prevremena ruptura plodovih ovojaka može dovesti do remećenja aktivne faze prvog porođajnog doba, te nenapredovanja porođaja i povećane incidence operativnog završavanja porođaja. ${ }^{15} \mathrm{U}$ našem istraživanju je zabeležen znatno veći postotak PROM-a u grupi žena, koje su porođene hitnim carskim rezom, a kao indikacijama dominira zastoj u napredovanju porođaja. Naše istraživanje je pokazalo znatno veći postotak plodova muškog pola, koji su rođeni operativnim putem, a interesantna studija iz osamdesetih godina prošlog veka, pokazala je da plodovi ženskog pola imaju znatno veću šansu za vaginalni porođaj, bez akušerskih intervencija, uz smanjen perinatalni morbiditet i mortalitet $u$ odnosu na plodove muškog pola. ${ }^{16}$

Karlični vaginalni porođaj može biti povezana sa većim rizikom od depresije na rođenju, ali ne i kasnijm posledicama, uz pažljiv i adekvatan tretman pri porođaju i neonatalnoj nezi. ${ }^{17}$

Između dve grupe ispitivani novorođenčadi nismo zabeležili statistički značajnu razliku u vrednostima Apgar scora u 5 minutu, imali smo 3 lake asfiksije (Ap 7) kod novorođenčeta iz grupe vaginalnih porođaja i 1 iz grupe rođenih carkim rezom, bez razlike u dužini boravka u jedinici intenzivne nege. Slično izveštajima drugih autora, nismo zabeležili razliku u neurološkim poremećajima i porođajnim traumama neonatusa između ispitivanih grupa. ${ }^{18}$

\section{Zaključak}

Vaginalni porođaj pri karličnoj prezentaciji ploda, predstavlja prihvatljiv akušerski izbor, pri adekvatnom odabiru pacijenata. Porođaj se obavlja uz pažljiv i ekspektativan pristup iskusnog akušera i prisustvo neonatologa na porođaju. Uz poštovanje principa dobre akušerske prakse, ne dolazi do povećanja perinatalnog morbiditeta i mortaliteta.Verujemo da politika planiranog carskog reza ne treba da bude jedini izbor, kao način porođaja kod karlične prezentacije ploda u terminu. 


\section{Literatura}

1. Cheng M, Hannah M. Breech delivery at term: a critical review of the literature. Obstet Gynecol 1993;82:605-18.

2. Ford J. Recurrence of breech presentation in consecutive pregnancies. BJOG 2010;117: 830-836.

3. Doyle NM, Riggs JW, Ramin SM, Sosa MA, Gilstrap .LC 3rd.Outcomes of term vaginal breech delivery. Am J Perinatol 2005;22:325-8.

4. Ghosh MK. Breech presentation: evolution of management. J Reprod Med 2005;50:108-16.

5. Su M, McLeod L, Ross S, Willan A. Factors associated with adverse perinatal outcome in the Term Breech Trial. Am J Obstet Gynecol 2003;189:740.

6. Hofmeyr GJ, Hannah ME. Planned caesarean section for term breech delivery. Cochrane Database Syst Rev 2003; 2:CD000166.

7. Hannah ME, Hannah WJ, Hewson SA, Hodnett ED, Saigal S, Willan AR, et al. Planned caesarean section versus planned vaginal birth for breech presentation at term: a randomised multicentre trial. Lancet 2000;356:1375-83.

8. Mishra M, Sinha P. Does caesarean section provide the best outcome for mother and baby in breech presentation? A perspective from the developing world. Am JObstet Gynecol 2011;31:495-8

9. RCOG The Management of Breech Presentation. Guideline No. 20b 2006

10. ACOG Committee Opinion Mode of term singleton breech delivery. Obstetrics \& Gynaecology 2006; 108:235-7.

11. Goffinet F, Carayol M, Foidart JM, Alexander S, Uzan S, Subtil D,et al. PREMODA Study Group. Is planned vaginal delivery for breech presentation at term still an option? Results of an observational prospective survey in France and Belgium. Am J Obstet Gynecol 2006;194:1002-11

12. Second MAF, Nassar AH, Usta IM, Melhem Z, Kazma A, Kallil AM. Impact of advanced maternal age on pregnancy outcome. Am J Perinatol 2002; 19: 1-7.

13. Andrews K, Menticoglou S, Gagnon R. Vaginal delivery of breech presentation. Int J Gynecol Obstet 2009:226:557-566

14. McNamara JM,Odibo AO,Macones GA,Cahill AG. The effect of breech presentation on the accuracy of estimated fetal weight. Am J Perinatol 2012; 29:353-60

15. Kotaska A,Menticoglou S,Gagnon R,Farine D,Basso M,Bos H.et al. Vaginal delivery of breech presentation. : JOGC 2009; 31557-66

16. M H Hall, R Carr-Hill et al. Impact of sex ratio on onset and management of labour. BMJ 1982;285:401

17. Nelson KB, Leviton A. How much of neonatal encephalopathy is due to birth asphyxia. Arch Pediatr Adolesc Med 1991;145:1325-31.

18. Glezerman M. Five years to the term breech trial: the rise and fall of a randomized controlled trial. Am J Obstet Gynecol 2006;194:20-5.

Autor za korespondenciju:

Dr Radenka Mijailović Borlja

Bolnica za ginekologiju i akušerstvo KBC Zemun-Beograd,

Vukova 9, Zemun,

tel.062253009,

rborlja@gmail.com 